\title{
Educational Resources Developers' Copyright Protection: Civil and Labour Law Issues
}

\author{
Tatyana Kasyanenko, ${ }^{1, *}$ and Maria Rodina $^{1}$ \\ ${ }^{1}$ Don State Technical University, Gagarin sq., 1, Rostov on Don, 344003, Russia
}

\begin{abstract}
Digital technologies development, expansion of distance learning forms application have given rise to the necessity of creating and placing substantial content both on open educational resources and those infrastructure websites of educational institutions with restricted access. This, in its turn, has led to the questions about authors and copyright holders of the content, distribution of renumeration from its commercial use, as well as the protection of the rights of subjects whenever there are violations of rights. Following a comparative legal analysis of the legislation of the Russian Federation and foreign countries, there is drawn a conclusion on the necessity of the additional development of educational resources developer's copyright protection mechanisms.
\end{abstract}

\section{Introduction}

From a historical perspective, copyright emerged as a time-limited privilege granted to authors and publishers due to the importance of their activities to society [1]. Subsequently, under the influence of the spread of the theory of the right to claim [2] and the idea of the proprietary nature of intellectual rights [3], such a privilege was transformed into the law and a different place was assigned to social usefulness of the authors' activities [4]. The above argument seems to be very relevant for a significant number of commercially used objects of copyright, however, the results of the creative activity of teachers of universities and higher education should meet, in our opinion, the criteria of usefulness to society and, above all, follow scientific and educational goals.

The widest introduction of distance education has entailed the need to develop and implement extensive educational resources, including open educational platforms, the most famous of which are Coursera, Open Edu, EXD and others, including the development of the Open Education Recourses project under the auspices of UNESCO. In addition, universities place on their own educational platforms multimedia presentations, digitized lecture materials, online courses, recordings of webinars and conferences, recordings of lectures by teachers, online projects of students and listeners, etc. The posting of the content is carried out among other things for commercial purposes.

The development of online forms of education, the use of special educational software products, while solving the problems of accessibility and non-discrimination in the field of

* Corresponding author: kasjants@,yandex.ru 
education, predetermines the need to resolve a number of theoretical and practical problems, which, in our opinion, should include the following: defining the objects subject to legal protection, classification of these objects, delineating copyright of teachers, and the exclusive rights of the universities themselves to the results of employee performance, to determine cases of legal free use of such resources both by ordinary users and in the educational process of other educational institutions, etc. These circumstances predetermine the relevance of the research topic in question.

\section{Materials/Methods}

The following works by Russian scientists - V.L. Antin, V.O. Kalyatin, E.A. Sviridova, A.S. Vorozhevich, N.V. Kozlova and others - and foreign researchers - Sophie StallaBourdillona, Eleonora Rosati, Justine Pila, Chuhgan Wang, Ruth L. Okediji, Ole-Andreas Rognstad and others - underlie the research in question. Methods of comparative jurisprudence, dialectics as well as systematic structural analysis underlie the methodology of the research in question.

\section{Outcomes}

Earlier, we pointed out that the basis of educational resources created by higher education is made up of various kinds of multimedia presentations, digitized lecture materials, online courses and their recordings (including those transmitted to open educational platforms), records of lectures by teachers (hereinafter referred to as an educational product (s)), as well as their integrating software. In addition, educational resources can also contain the results of scientific research - research reports, excerpts of scientific articles, monographs, etc. (Fig. 1.). Each of the named objects should be correlated with the concept and features of the objects of copyright of the Russian Federation.

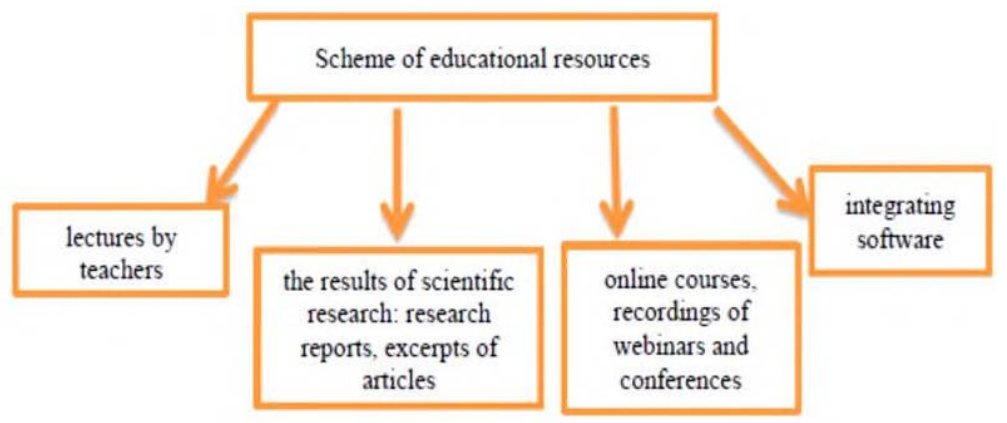

Fig. 1. Educational resources

The civil legislation of the Russian Federation defines works of science, literature and art as the object of copyright, regardless of the merits and purpose of the work, as well as the method of its expression (Article 1259 of the Civil Code of the Russian Federation). This list is not exhaustive.

Moving on to consider in more detail the signs that make it possible to classify works as copyrighted objects. The most important criteria for classifying objects as works (within the meaning of Article 1259 of the Civil Code of the Russian Federation) is the fact of their creation by the creative work of the author. Creativity in the broadest sense is an intellectual activity, the result of which is the creation of a previously unknown intellectual product [5]. 
The judicial practice established in Russia is based on the presumption that the result of intellectual activity was created by creative labor, until proven otherwise. It should be noted that the criterion of originality, which is given great attention in a number of countries, is not the only one so significant in Russian practice. As noted by the Supreme Court of the Russian Federation, the lack of novelty, uniqueness and (or) originality of the result of intellectual activity in itself cannot indicate that such a result was not created by creative labor and, therefore, is not an object of copyright [6].

The second most important criterion is the expression of the work in an objective form (clause 3 of article 1259 of the Civil Code of the Russian Federation). It should be noted that this can be a written, oral, electronic form, an image form, audio or video recording, a volumetric-spatial form (clause 3 of article 1259 of the Civil Code of the Russian Federation). Registration of a work is not required for the emergence, exercise and protection of copyright. A significant part of the content posted by educational organizations is a work of science, expressed in writing or in writing, or in audio-video visual form.

Of particular interest, in our opinion, are such types of educational resources as multimedia presentations and specially recorded online courses. Multimedia presentations can include photographs, video clips, text and statistics, and audio. Such works, in our opinion, should also be qualified as complex objects that include several results of intellectual activity protected by law. Within the meaning of the law, a complex object is a single whole completed work, in which the impossibility of using at least one of its component parts will lead to the loss of the author's intention of the creator of the complex object, as a result of which the integrity of the result of intellectual activity will be violated and its further use will become impossible. A similar conclusion should be drawn about the complex legal nature of an online educational course. It, as a rule, includes a series of videos in which the course leader is captured (one or more, not necessarily coinciding with the author of the script and text), his speech is accompanied by a presentation that duplicates the meaning of the reproduced text, sometimes with audio and photo. filling. In addition, the courses include test assignments (tests, creative assignments).

It seems more difficult to characterize an educational resource that combines a number of educational products. An educational resource should be understood, on the one hand, a specially developed computer program (including operating systems and software systems, presented in an objective form, a set of data and commands intended for the operation of computers and other computer devices in order to obtain a certain result, including preparatory materials obtained during the development of a computer program, and the audiovisual displays generated by it), and on the other hand, a database that unites a variety of educational products (works). Computer programs are protected by copyright within the meaning of the Civil Code of the Russian Federation as a work, and on the other hand, may be subject to patent law. Consequently, at least two legal protection regimes operate in relation to the educational resource: as computer programs and databases, and works.

In the context of the problem under study, the UNESCO project "Open Educational Resources" is of interest (Eng. Open education resources (OEP)). This term was first announced in 2002 at the UNESCO Forum on the Impact of Placement of Teaching Materials for Higher Education in Developing Countries. According to a study conducted under the auspices of UNESCO, the named resources can be defined as resources for teaching and learning in any medium, digital or otherwise, that allow free access, use, reuse and transmission by others. OEP Resources are resources obtained from copyright holders under an open license or partially limited license [7].

Paris Declaration on Open Educational Resources 2012 encourages States to promote public awareness of the use of such resources; encourage their use to expand access to all levels of education, help create an enabling environment for the use of information and 
communication technologies, support capacity-building for the sustainable development of quality teaching materials; support institutions, provide training and motivate teachers and other staff to produce and share high quality and affordable educational resources, taking into account local needs and a wide variety of learners; to promote quality assurance and professionalism, to encourage the development and adaptation of OEP to different languages and cultural contexts and much more [8].

Undoubtedly, the implementation of the open educational resources project is faced with the national peculiarities of copyright and the need to protect the rights of authors in different countries, and also partly increases the objective conflict of interest between the needs of protecting the interests of copyright holders and ensuring access to knowledge and education, eliminating restrictions and discrimination in the field of education in development interests of all countries and regions of the world.

At the same time, the legislation of a significant number of countries contains instructions on cases of free use of copyright objects, including educational resources. Free use concepts in their most general form can be presented in two variations. The first approach is based on the doctrine of fair use [9]. When assessing the fairness of such use, special attention is paid to such circumstances as the purpose of the use, including commercial or non-commercial nature (however, the doctrine of fair use is not often applied to justify exclusively non-commercial use [10]); the nature of the work (the higher the level of creativity, the more likely the use can be qualified as a violation [11]); the volume and materiality of the borrowing in relation to the protected work; the impact (positive, negative) that such borrowing may have on the potential market or value of the protected work [12]. When considering a specific case, the courts apply and evaluate such criteria individually [13].

The second approach, characteristic of continental European law, defines the content boundaries of exclusive rights and establishes specific cases when the free use of someone else's work is allowed [14]. Such cases, as a rule, include the way of use (reproduction, distribution, etc.), the purpose of use, the scope and scope of use. Directive 2001/29/29 / EC of the European Parliament and of the Council of the EU of 22 May 2001 "On the Harmonization of Certain Aspects of Copyright and Related Rights in the Information Society" [15] allows states to establish restrictions on exclusive rights, for example, in such cases as illustrations intended for teaching, quotations cited in criticism or review, for noncommercial research or private study, and others.

At the European level, the provisions of Directive (EU) No. 2019/790 on copyright and related rights in the digital single market, which was approved by the European Parliament on April 17, 2019, are also of interest. negative reviews [17]. With regard to the issues we are investigating, of particular interest is Article 5 of the said Directive (EU), which introduces mandatory limitations and exceptions, allowing the use of works or other protected objects in digital and cross-border educational activities solely for the purpose of illustration in educational activities and to the extent that it is justified by the noncommercial purpose of use.

It should be agreed that all educational institutions recognized by the EU Member State, including those related to primary, secondary, vocational and higher education, can use this provision [18]. It is important that the organizational structure and funding of an educational institution should not be decisive factors in determining the non-commercial nature of a particular educational activity (paragraph 20 of the preamble). The digital use of protected content should be carried out under the responsibility of the educational institution, on its territory or in other places (outside the premises of educational institutions, for example, in a museum, library) or through a secure electronic environment (subparagraph (a) of paragraph 1 of Article 5) and must be accompanied by an indication of the source, including the name of the author, unless this is not possible (subparagraph (b) of 
paragraph 1 of article 5). Such limitations / exclusions should apply both for face-to-face training (using electronic boards and similar devices) and for distance learning delivered in a secure electronic environment (for example, access to online courses). As a general rule, the use of protected content for educational purposes presupposes the use of fragments of works or their parts, while such use should not threaten the existence of a market for educational content [19]. However, EU member states may not apply this exemption to specific uses or types of content intended primarily for the educational market, if the license obtained for the use of digital content is available. Countries can also provide authors and rights holders with fair compensation at the national level.

A study of the experience of the legal regulation of Chinese copyright in relation to these resources showed that Article 22 of the Chinese Copyright Law establishes the rules of fair use. Thus, they can be used without permission or remuneration of the copyright holder, provided that the copyright holder is identified and other rights of the copyright holder are not violated. However, for the use of such material in an educational context, it is only permitted to translate or reproduce the source in a small number of copies for use by teachers in the classroom or in scientific research, provided that the translation or reproduction is not subject to publication or distribution. Consequently, this provision is generally only applicable to physical classes, which does not allow such provisions to be implemented in relation to OEP manufacturers who host their courses on the Internet.

In 2006, China adopted the Ordinance on the Protection of the Right to Network Dissemination of Information. This document consolidated an exception to the general provisions of the law, indicating that such resources can be used for the purposes of poverty alleviation, disease prevention and treatment, disaster prevention and relief, through the information network free of charge, provided that the specific network service provider post the relevant information related to the work, and the respective author has no objection to downloading and distributing their work. This means that because the website provides educational information for specific purposes, it may use copyrighted material without the permission of the copyright holder. [20]

Similar rules on the possibility of free use of works for special purposes are reflected in the current legislation of the Russian Federation. The use of a work of science, literature and art by any means, both specified and not specified in paragraphs $1-11$, paragraph 2 of Art. 1270 of the Civil Code of the Russian Federation, regardless of whether the corresponding actions are performed for the purpose of making a profit or without such a purpose, is allowed only with the consent of the author or other rightholder, except for cases when the Civil Code of the Russian Federation allows free use of the work. The Civil Code of the Russian Federation establishes a fairly general list of exceptions (restrictions) of the author's exclusive rights.

Of greatest interest in the context of the topic of this study is lawful use for personal purposes, which involves the free reproduction of a work carried out by a citizen for the subsequent non-commercial use of a legally obtained copy to meet his own needs and the needs of the ordinary circle of the family of this citizen. The important thing here is the way of use (reproduction), the purpose (as a rule, a non-commercial purpose - the acquisition of new knowledge), the legality of obtaining a copy (for example, if an educational institution has posted educational content on its website in the public domain, then the legality of its reproduction is obvious. illegal copying of certain materials from the university website and their subsequent reproduction, albeit for personal purposes). The second limitation is related to the freedom of use and subsequent distribution of works for informational, scientific, educational or cultural purposes (including lawful quotation, illustration). In this case, the important thing is the obligation to indicate the author of the work and the source of borrowing, as well as the compliance of the volume of use with educational goals. 
The last but not least most important issue in the context of protecting the rights of authors of educational resources is the definition of copyright holders of educational content. As a rule, the works considered in this article are created by a teacher of an educational institution, other specialists (engineers, programmers, video operators, etc.), and sometimes by students (listeners). The authors (teams of authors) of educational content are often employees of the university, however, both the author himself and the educational (scientific) organization can be the copyright holder of exclusive rights to these objects. The concept of understanding a work piece varies by jurisdiction. In the Russian Federation, when qualifying a work as a service one, the following facts are taken into account: whether the sphere of activity of the employer belongs to the one in which the intellectual property object was created, the work obligations of the person or the presence of a special order on the performance of a specific work, the place of work, the possibility of the employer's implementation of the creation process, the purpose of creation, the subsequent behavior of the parties, the terms of the employment contract itself. This interpretation is closer in meaning to the American concept of work for hire, according to which all property rights to the results of intellectual activity created within the scope of the labor function are transferred to the employer. At the same time, one should agree with the opinion expressed in the scientific literature that the mere existence of an employeremployee relationship will not give the employer the ownership of works created by the employee during the term of the relationship. This is also true if the work is relevant and useful to the employer, and the employee may have used the employer's time and resources to bring the invention to completion. For example, a teacher's employment contract usually does not contain an indication of the responsibility to develop online courses, or to record lectures. In addition, by reading one discipline, the teacher can carry out scientific research in another, related field and thereby create unique scientific content. It seems that in this case, the author himself will be the copyright holder and the placement of such results in the educational system of the university should be carried out taking into account the above exceptions (name of the author, obtaining consent for placement, non-commercial nature of use). A marker for determining whether the work is performed in accordance with the terms of the employment contract is the answer to the question of whether the performance of the work falls within those activities that the employer could reasonably expect from the employee [21]. In other words, was the work one that the employee could have focused on creating such an object. Consequently, not every work created by an employee of a higher educational institution falls under the concept of an official work, but in each specific case the issue is resolved by referring to the features indicated above.

\section{Conclusions}

The study showed that the problem of illegal use of educational content and the protection of the rights of authors and copyright holders of the said content is widespread, especially for open educational resources. The combination of the possibility of establishing restrictions and exemptions in legislation, including those related to the use of educational resources of other universities for personal purposes, or for scientific and educational purposes, and minimizing the negative consequences of such use for the commercial market of educational resources, remains difficult for a judicial assessment. The issues of using digital copies of educational products are not fully resolved either. Minimizing disputes between employees and educational institutions regarding the exclusive rights to educational content will be facilitated by a clear description in the employment contract of specific parties of those types of works that may result from the performance of the labor function, and the determination between the parties of the conditions for using such results. 


\section{References}

1. Beckerman-Rodau, The problem with intellectual property rights: subject Andrew matter expansion. Yale J. L. \& Tech (2011) https://digitalcommons.law.yale.edu/yjolt/vol13/iss1/2

2. R. M. Merges, What kind of Rights are Intellectual Property rights? R. C. Dreyfuss, J. Pila. The Oxford Handbook of Intellectual Property Law. Oxford University Press, 1010 (2018)

3. O.-A. Rognstad, Property Aspects of Intellectual Property. Cambridge University Press. 244c. (2018) Concepts of Property in Intellectual Property Law. Cambridge University Press, 316 (2013)

4. V. Antin. Copyright in Virtual Reality (New Opportunities and Challenges of the Digital Age), 216 (2017)

5. E. Sviridova, Legal Aspects of Commercialization of Results of Intellectual Activity of Educational State-Funded Organizations. Economics. Taxes. Law. 12(1), 152-163 (2019)

6. Resolution of the Plenum of the Supreme Court of the Russian Federation dated 23.04.2019 No. 10 "On the Application of Part Four of the Civil Code of the Russian Federation". Rossiyskaya Gazeta, 96, 05/06/2019

7. S. Hoosen, Survey on Governments' Open Educational Resources (OER) Policies. UNESCO and Commonwealth of Learning, 27 (2012)

8. F. Miao, S. Mishra, R. McGreal, Open Educational Resources: Policy, Costs and Transformation. UNESCO and Commonwealth of Learning, 234 (2016)

9. J. D. Lipton, Law and Authors: A Legal Handbook for Writers. University of California Press, 272 (2020)

10. V. Kalyatin, On the Prospects for the Application of the Doctrine of Fair Use in Russia. Law. 11, 40 - 47 (2015)

11. J. Hughes, Fair use and its politics - at home and abroad. Copyright Law in an Age of Limitations and Exceptions. Cambridge University Press, 528 (2017)

12. A. S. Vorozhevich, N. V. Kozlova, Cases of Free Use of Objects of Copyright: Essence, General Overview. Civil Law Bulletin, 5, 43 - 78 (2019)

13. N. Snow, Who Decides Fair Use - Judge or Jury? Washington Law Review, 94(1), 281 -282 (2019)

14. J. Pila, P. Torremans, European Intellectual Property Law/ Oxford University Press. $671(2016)$

15. 2001/29/EC of the European Parliament and the Council of 22 May 2001 on the harmonisation of certain aspects of copyright and related rights in the information society. Official Journal of the European Communities, 22.6.2001

16. S. Stalla-Bourdillona, E. Rosatia, K. Turkb, An academic perspective on the copyright reform. Computer Law \& Security Review, 33(1), 3-13, (2017)

17. M. Kretschmer, S. Dusollier, P. Bernt Hugenholtz, C. Geiger, The European Commission's public consultation on the role of publishers in the copyright value chain: A response by the European Copyright Society, European Intellectual Property Review [E.I.P.R.], 36(10), 591-595 (2016)

18. M. Ricolfi, R. Xalabarder, M. van Eechoud, Academics against Press Publishers' Right, Statement from 169 EU academics (2018) 
19. S. Stalla-Bourdillon, Rosati A Brief Exegesis of the Proposed Copyright Directive (2016)

20. D. A. Motovilova, Key Provisions of Directive (EU) No 2019/790 on Copyright and Related Rights in the Digital Single Market. Journal of the Intellectual Property Rights Court. 26, 106-120 (2019)

21. C. Wang, G. Zhao, Open Educational Resources in the People's Republic of China: Achievements, Challenges and Prospects for Development. UNESCO Institute for Information Technologies in Education, 86 (2011)

22. M. J. Davison, A. L. Monotti, L. Wiseman, Australian Intellectual property law. Fourth edition, 1063 (2020) 